\title{
ELEMENTS OF PRACTICAL REALITY ${ }^{1}$
}

\author{
Florian Znaniecki
}

Every phenomenon that could be considered a single element of a certain multiplicity, we call an element; the collection of all phenomena constituting the material of activity we call practical reality. We include here thus all phenomena that are usually defined as motives, aims, means, and the results of acting, regardless of whether they relate solely to the individual or whether they have a social nature. Thus both sensory phenomena and cultural phenomena, that is, those which appear in sensory form yet have significance that is not exhausted by their sensory content, are included here. For the time being, though, we understand activity solely as a process of conscious transformation: the changing of phenomena, in either their sensory form or their cultural significance. Therefore, it is obvious that our entire experience, without exception, can be viewed as practical reality, because there are no phenomena that cannot be changed and that have not been changed by humans in conscious life. Even phenomena that are apparently in their nature entirely independent of our activity (for instance, astronomical phenomena) change their significance in accord with the development of thought about them, or, in other words, they are not only natural phenomena, they are also cultural phenomena. The designation of practical reality and its elements cannot thus be accomplished with the help of a simple indication and the separation of a certain group of phenomena from other groups, but only by discovering those general characteristics

\footnotetext{
${ }^{1}$ Originally published as "Elementy rzeczywistości praktycznej” in Przeglad Filozoficzny, vol. 15 (1912), pp. 161-187. The translation is based on a reprint of the paper featured in the first volume of Znaniecki's collected works ("Myśl i ržeczywistośs" i inne pisma filozoficzne, ed. J. Wocial, Państwowe Wydawnictwo Naukowe (1987)).
} 
thanks to which any phenomenon becomes an element of practical reality, a link and material of activity.

The above definition is thus solely temporary in the sense that it is not at all the result of theoretical reflection on an element of practical reality but is a departure point for such reflections. Our task will be to designate elements of practical reality, that is, to reveal the traits thanks to which a phenomenon is a link in activity. Our task, however, is not theoretical reflection on activity; we will content ourselves with indicating the processes labelled by the term, which are known to everyone. In actuality, we are compelled to designate elements of practical reality on the basis of their relation to activity; yet to this end, defining activity as the process of a conscious change in phenomena is entirely adequate.

\section{I}

According to a theory that is today very widespread, ${ }^{2}$ science is the continuation of practical thought: activity defines the general outlines of that reality known to the science of nature; the process of those thought functions featured and elaborated in full in the process of scientific research has its beginning in activity.

This theory is correct in every regard. Above all, it takes into consideration the significant historical order of succession of types of thinking: knowledge developed later than practical activity. It also emphasises, entirely correctly, the importance of practice as a basic factor in the genesis of cognition. But the very process of that genesis gives it a false significance. It is not true that activity itself found its further course in cognition so that the form which today we find or produce in scientific study of the natural world should be merely the perfection of that form which the world assumed for practical life. This last form exists till this day as something fundamentally different from the type of the theoretically studied world. Activity created - and has been creating to this point - only certain thought sequences, which in developing produce cognition, but each of which, taken as a whole, constitute the sole link of the practical process within whose boundaries it arose. The first and last element of this sequence, that is, the initial situation, which theoretical reflection is to resolve, and the result of reflection, constituting the departure point for further activity,

${ }^{2}$ Cf. H. Bergson, Evolution créatrice, chapter III, E. Le Roy, "Science et philosophie," Revuede Métaphisique 7; H. Poincaré, Science et hypothèse; Wilbois, La Méthode des sciences physiques. The pragmatic part contains this statement. Cf. also E. Mach, Erkenntnis und Irrtum. 
are undeniably conditioned by the entire practical process in the course of which they appear, but the passage from the first element to the last, the choice of intermediary elements and their mutual relation - in a word, what is properly cognitive in resolving a practical situation - distinguishes itself as something fundamentally different from the whole process of activity. The longer the path between the elements at the extremes - the situation and its resolution - the richer, the more varied, and the more independent will be the internal relations of that theoretical sequence and the more independence the study will acquire. So in the course of the development of conscious life ever longer, richer, more theoretically complex theoretical sequences are created. In the end, the division of social work causes such a theoretical sequence to fill a large part of the life of certain human individuals. Then a given theory can still be considered as one element of practical life, in so far as we take it in connection with the whole of social life: it most often arose on the basis of a social-practical situation and will render a social-practical service. But for the individuum creating it, it will be solely a theory, without connection to practical life. The first and last member, the practical situation and its resolution, will be entirely forgotten. The relation between knowledge and activity is reversed: for a given individuum (or even a given group - a scientific body) it is no longer practical activity that will define the departure point and task of theoretical thinking, but on the contrary, the theoretical situation will designate the basic elements for that separate type of activity that is cognitive thinking. In a word, what happens is that the choice and relation of phenomena in the theoretical sequence will be entirely independent of practical substance.

This is the level of evolution on which natural science finds itself. Obviously, the type of reality it studies can have nothing in common with the type of reality with which activity in itself deals - that activity which produces a theoretical sequence as one of its own links. It is also obvious that cognitive thinking, considered solely in terms of its object - the association of phenomena in theoretical sequences - will be something fundamentally different from a practical thought. Even then, when we note that the very creation of scientific theories is a certain kind of activity, we must be aware that that activity - to the degree that it is already adapted to the requirements of the theoretical situation - acquires traits that are entirely its own: from an activity it becomes cognitive thought. In fact, this self-adaptation never appears at once but is rather achieved gradually; even in individual scientific thinking the association of phenomena or theoretical views is from the beginning practical to a lesser or greater degree and only by way 
of eliminating practical factors and introducing ever more new theoretical relations does it come closer to having a purely theoretical character. But only then, when the given association of phenomena or views achieves that nature, is the theory ready and its elaboration will be something fundamentally different than the process that brought it to the level of theory. In the evolution of knowledge, the life process of accepting new theories and rejecting old ones will be practical, but never the thought process, which as a logical function associates elements of theory with each other, extends the theory to new experiences, or combines more specific theories in a more general system. In short, knowledge, on account of its historical connection with other areas of individual and social life, is a phenomenon of a practical nature on account of its relation to the material it elaborates theoretical thinking.

Scientific creativity can be placed in an even row with other types of creativity: moral, aesthetic, and religious. All these types of creativity gradually came to be differentiated within practical activity and have the same general basic traits, but to these are added specific new ones, differentiating those types of creativity from one another and separating them from their common practical base. The development of these specific traits goes in tandem with the creation of combinations of phenomena, which are independent on the inside from the general practical process; in associating the phenomena, inside every combination, thought processes occur in which those specific traits differentiating them from activity in general have dominant significance. On the exterior, however, each of these relations, considered as a whole, is a link in practical life, and a distinct cognitive, aesthetic, moral, or religious thought may at any moment enter the composition of its practical base.

A moment comes, however, when theoretical creation turns back from nature, which was its proper subject, and chooses as its subject that activity from which it proceeded. The same can happen in regard to aesthetic, moral, or religious production. Here is not the place to speak of this. Let us also omit the fact that in the historical process, theoretical creation began from self-reflection, avoiding for the moment its source. It is sufficient that through itself it led to activity. The circle was closed. Theoretical situations, which were previously imposed only by the natural world, are finally imposed by activity itself. It is understood, however, that that activity here appears as if from the exterior, not in the very process, in which at one time cognitive thought imposed its own issues. Cognitive thought creates issues 
from activity, as its material. Confusing the departure point with the arrival point is impossible.

Then, however, it emerges that - as we said - practical reality can have nothing in common with natural reality. We are more completely convinced a posteriori of that which a priori is obvious.

The basic difference, which jumps to the eye at once, is that natural reality is a world of being, while practical reality is a world of values. Let us, however, give closer consideration to the significance of this distinction.

Without exception, everywhere where philosophy has introduced the distinction, it has been based on that trait of practical reality which reality possesses originally, before it becomes the object of cognitive, scientific thought. What is of value for philosophy is whether a thing is positive or negative, and in accordance with which the subject occupies a position, accepts or rejects a thing, and so forth. It is less concerned with whether the subject is creating an absolute value, always occupying the same position, as, for instance, in Kantism and Fichteanism, or is a subject creating a relative value, changing its position, as in various ethical, aesthetic, or religious types of empiricism.

And yet, such a definition of practical phenomena is not fully suited for the theory of such phenomena, since it takes the practical world as it appears before theoretical thought begins to study it; it takes it then when it is still a departure point and not an arrival point in that circle we mentioned above. From the world of values, positively or negatively appraised, knowledge, morality, art, and religion emerged. In this form, practical life cannot be grasped in any theoretical system, because in this form it creates its own theoretical systems, including moral, aesthetic, and religious ones. The combination of values based on their appraisal, on the position of the subject in relation to them, expanding and harmonising, leads to cognitive theories, to positive morality, to works and streams of art, to historical religions, in a word, to all those series of phenomena which - each considered separately as a whole and all together as historical facts - constitute what we could call "higher-order values." That same relation of value conceived by theoretical thought cannot lead to a theory of value, because it is approaching value here from the opposite side; we close the circumference of the circle in which theoretical thought distanced itself from activity in the direction of independent study of natural phenomena and returns to the same activity as to its object.

They say to us: but there are countless theories which arose on the basis of the laws of that pre-reflective activity. That is so. But each of those 
theories betrays, by its behaviour, that that basis is not appropriate for it. Various ethical views are typical here. Each of them, in that which is apparently a theory of moral facts, does nothing more but raise to consciousness that practical life system of morality that was formed independently of it in a given era and in a given society. ${ }^{3}$ In addition, it tries theoretically to justify that system and this never works: no moral conclusion ensues from a theoretical statement of some fact or law in itself. What is worse, however, is that it always turns out that life morality does not correspond to ethical requirements. The system of positive morality in every era and society is, for cognitive thought, illogical and incomplete; the norms contradict each other; human acts contradict the norms, and they are unrelated to one another.

Thus there is that strange idea of normativity. Life creates moral systems; an ethics arrives, and being unable at once to produce those systems on the established bases, it creates a new system and demands that life adapt. A science that waits until reality, in its development, makes its statements real.

The same concerns aesthetics, philosophy, religion, and even to a certain degree, logic, although in the latter, reflective thinking is a little closer to original thinking. In defining a value as something in regard to which a positive or negative position is adopted, of necessity such a theory of value must be reduced to the assertion that value opposes existence, as that which must or should be opposes that which is. Life itself, after all, in producing cognitive, aesthetic, moral, and religious creations, builds relevant systems on the basis of a choice of appraisals. Every confirmation of values or their relation contains implicite what James calls a "claim" to be recognised as absolute; justifying that demand consists in likening it to other demands of the same order stated by the same individual or others. This is the way moral, ${ }^{4}$ artistic, religious, and finally, ever more objective scientific systems are built. Reflective thinking sets this system its own task, depending on the era, environment, and individual; being unable to wait until life systems make it real, it presents a value as that which should be, expressing here equally the expectation of life values, in order for their absoluteness to be recognised, as well as its own expectation that that recognition of the absoluteness of life values be in accord with its requirements.

\footnotetext{
3 Cf. L. Lévy-Bruhl, La morale et la science des moeurs, Paris-Alcan.

4 The work by Frédéric Rauh, L'expérience morale, is an interesting and important attempt to create a critical method for the construction of moral systems. This method, mutatis mutandis, could be applied to esthetic and religious life; W. James's Varieties of Religious Experience contains numerous ideas that could be used in this regard.
} 
Let us understand now that knowledge, of which values themselves are supposed to be the object, must absolutely eliminate the understanding of values as something positive or negative and their definition as that which should be. Such a science must first of all be aware that it approaches activity not from inside but from outside, and that through the very fact of its own existence it is dealing not with activity as a primary source of systems but with activity as a material of the system.

In this regard then, in order to avoid confusion in terminology, we propose the use of the term "a good" for a value as an object of appraisal or as that which "should be." A "value" and a "good" would signify the same phenomenon but viewed from different viewpoints: a "good" would be a value in its purely practical, life relation to other values; a "value" would be a good considered theoretically in its relation to other goods as a research subject. In the circle that consciousness delineates - rising from practical life to the study of the natural world and returning from there to the study of practical life - a "good" would indicate an element of practical reality as a point of departure, a "value" an element of practical reality as a point of entry.

On this ground, the question of designating elements of practical reality would be expressed in the following manner: what are the traits of a phenomenon thanks to which it is a value, that is, the link of activity understood as a subject of scientific study.

As these traits are, obviously, common to all values, thus the concept of value will be the most general of all the concepts applied to elements of practical reality; its content will be the most general form that those elements adopt for cognition and will become the basis for all more specific forms, all definitions that the science of values will give to practical phenomena. In a word, the concept of values will be a thought category for elements of practical reality and simultaneously a category of those same elements as objects of cognition.

\section{II}

In order to establish the significance of the concept of value, we have the path indicated by our previous reflections. Cognitive thought, in liberating itself, constructs knowledge of nature and only from that point turns to activity. It is easy thus to imagine that it transfers to practical reality those forms that it used for natural reality, and even those cognitive generalities that it acquired in studying nature. It should thus be considered whether 
such a transfer is possible and if not to contrast the practical phenomenon with the natural one, describing value in the proper manner.

The form constituting the logical basis in studying the natural world is the category of things, that is, substance. All other categories ${ }^{5}$ are logically connected with it inextricably. The thing (substance) is a subject of thought which remains basically the same when it is being thought and however many times it is thought. Now natural cognition applies this thought postulate to reality. The thing (substance) is supposed to be objectively unchangeable. But it changes and in various moments appears variously. Thought can accept this only on the condition that that variety is the supplement of unchangeable properties to an unchangeable substance: that $A$ could be $A_{1}, A_{2}, A_{3}$, only then, when $A_{1}=A+x, A_{2}=A+y, A_{3}=A+\%$ Where does this addition of properties itself come from, though? In certain cases, thought ascribes the fault to itself: the property adhered to the subject earlier but was not cognitively distinguished. $A$ was actually $A+x+y+z$ : an error occurred. In other cases, however, it has to be accepted that the property did not exist and now it does - if only then when it appeared in the course of studying things - and cannot be viewed as a discovery. Then the property is a state; it is something real added to the substance. Since the substance itself cannot change, then by reason of this state the property must lie outside of it, in its relation to another substance.

Of course, as it deepens, further evolution is necessary here: the gradual distribution of the substance and simultaneously giving a material - that is, a logically inalterable character - to the changes themselves; the development and expansion of the idea of function proceeds from there. ${ }^{6}$ But the original categories give the direction of that evolution: the mathematicalnatural function is an association and distribution of material elements. It defines itself always by divisible static moments; ${ }^{7}$ only by way of a logical leap does it arrive at continuity, ${ }^{8}$ there where natural reality is not an obstacle, that is, in pure mathematics. Even though we have recognised that precisely there it has liberated itself from dependence on former geometric and arithmetic forms with their static and divisible nature, nevertheless its application to natural changes remains, and must remain, forever conditioned by the logic of the substance. Those changes are defined and differentiated in relation to the given natural order, and that order is entirely

\footnotetext{
${ }^{5}$ We here make use of Wundt's division of the category.

${ }^{6}$ See E. Cassirer, Das Erkenntnisproblem and Substranzbegriff und Funktionsbegriff.

${ }^{7}$ H. Poincaré, Nature du raisonnment mathématique (La Science et le'bypothèse).

${ }^{8} \mathrm{H}$. Bergson, Evolution créatrice, passim: Wstep do metafizyki, passim.
} 
based on substantiality. Mechanical, chemical, and biological changes are changes to a body. Even when certain phenomena, at today's level of the development of knowledge, are at once considered to be pure processes, yet those processes occur within the substantial world; they are processes in relation to the things that surround them. Even if the logical ideal of natural knowledge - the complete transformation of substance into function, the disassembly of things into relations - were ever to be achieved, the scientific system would always remain an expression of the world of things, its literal translation, the breakdown of bodies, properties, and states through the prism of functionality. It would always be an explanation - or description - of the given world in the material form and its final task would always be to order that precise world.

Let us consider now whether a value, an element of practical reality, appears in experience and can be conceived of in the same way as a thing, that is, does it possess a substantial nature?

First of all, it must be stipulated that expressing a thought concerning a value must occur in the same way that expressing a thought about things, as speech was shaped - for reasons that we cannot study here - in accord with the type of natural thinking. A value will always be an object of judgement and as such it will bear the external form of a thing. But cognitive thought is freeing itself in the course of its development ever more from the rule of grammatical forms, and not necessarily by way of artificial symbolism but simply with the aid of such grammatical associations that allow for replacing the relation of expressions - with the relations of phenomena themselves. The relation of subjects in cognitive thought frees itself from the relation of the symbol. Thus we can entirely think of a value other than in the category of a thing, to the degree that we only think of it as something real. Thus the conclusion follows that without the aid provided by speech, a value as a category of thought can only be described by the traits of the value as elements of experience.

Now while an element of nature, the subject of disinterested thought, can possess the trait of substantiality - can be conceived of as a thing that is unalterably the same - this cannot be said of a value. An element of nature after all is assumed to be independent from the thought of it; the premise is that theoretical thinking itself will not change it, though objective changes within certain bounds could be overlooked. At the same time, a value, when it becomes the subject of theoretical thinking, is already an element of practical reality, a link of activity. It is entirely marked by its property, by that belonging to a practical process; its entire reality consists in precisely this; in ex- 
perience it appears only as the link in an act. In no other regard can it appear, in no other character does it possess reality, either as an element of a naturalcausative relation or as a human "presentation," or as a creative work of the imagination, or as an object of faith. All these points of view emerge only together with the development of science, art, morality, and religion; here, while we are indeed considering a value in cognitive reflection, it is as an element of practical reality, thus avoiding all that that reality transforms in its various elaborations. For us, a value is only a link in activity, nothing more.

Thus given that alterability does not come to value from outside, it is obvious that it is not something added to it, to a lesser or greater degree, outside of thought. In so far as an object is a link in an act, it is fundamentally different from moment to moment, as the act is the very change of the object. A value, appearing only as a part of activity, as the subject of practical thought, is thus changeable in its very essence. This changeability does not allow it to be compared with any changeability of natural phenomena; it is neither a change of property nor a change of state. The fundamental error of the theory of the act, which we encounter in Bergson and certain pragmatists, consists in viewing it as a mechanical transformation of objects. Thereby, they give themselves first the natural world and then they place activity in that world - meanwhile, the natural world is, according to their own theory, the product of activity. The object, transformed by an act, does not appear as a material part of the natural world but only as a value; only theoretical reflection on the object of the act and the act begins to grasp the first as a material thing, and the second as a mechanical transformation of a material thing.

How then to understand that changeability of the value, if it is not either a change of property or a change of state? A glance at practical life allows us to answer the question. Change requires time. Thus an act is accomplished in time, or rather the time of practical reality is its form and work. The act is always present; it is produced in the present moment. The concrete present, in which we act, is not a moment detached from natural time sequenced in one line of an infinite quantity of past and future moments, and equal to them. It is an exceptional moment, privileged, and incomparable to any other. But it does not constitute, as Bergson believes, a blade of the past cutting into the future. On the contrary, the past and present begin from it; the past is its disappearance, the future, its emergence. It is at once the present and the act, or rather something from which the present and the abstract act were just separated. The concept of actuality expresses precisely this unity of the present moment and acting. Actuality creates the past, because it 
extracts values from the sphere of the present activity; it creates the future because it introduces values in that sphere. Values, appearing as an element of the act, appear in full in actuality. Activity moves them through the present moment by changing them, and it changes them by moving them through the present moment. The changeability of values can then be defined as an approach to or distancing from actuality, constituting a certain summit of their real existence; a value is real precisely in the measure that it is close to actuality. Finally, thus, it can be said that the changeability of values is simply their emergence and disappearance, with emergence and disappearance being understood as the process of acquiring or losing reality.

But that concrete and living actuality of the present act must not be confused with the detached and schematic actuality of psychology. Thus, it does not ensue from a value being most real when it is actual that outside of actuality it is not at all real. Wundt's principle, "as much reality as actuality" in the sense that reality is limited to the moment of consciousness, is applied only to psychology. Conducting it is possible only thanks to the division of scientific work, which arose because the world, in the natural view, was projected as independent of actuality, on the screen of substance; as constructing experience entirely with the aid of a combination of two substances - material and spiritual - turned out to be impossible, it was necessary to supplement the "objective" consequence of a phenomenon and contrast it with pure actuality itself: whence psychological "experiences." The proof that that path of recreating life actuality is not possible, however, is the unsolvable problem of psychic "temperaments."

In essence, practical actuality not only does not oppose the existence of phenomena outside the psychological "consciousness," but on the contrary, it requires it. Activity occurs in the present, but it looks to the future and extends into the past. It gives values duration in time by its existence itself. It knows that reality surpasses actuality in the past, because it leaves it changed and changing in its path, along the thread it is itself spinning. It knows that that reality surpasses actuality in the future because it sees how it approaches it and leads it by its own efforts. But that past and future of reality is not being: it is emerging, approaching actuality or retreating from it, nothing else. The existence of values is dynamic; it is a process, both outside of actuality and in actuality itself, through which a value passes, without stopping.

Finally, in the world of values, the understanding that schematically classifies phenomena into absolute past and absolute future phenomena, that counts as the past everything that passed through the present, and

\footnotetext{
${ }^{9}$ Cf. W. Wundt, Logik $\mathrm{III}^{3}$, p. 249 et seq., p. 260 et. seq.
} 
to the present what has not yet been accomplished, must be rejected. Our thinking still revolves here within a framework of the division between nature and psychological consciousness. In nature and in consciousness, what has happened cannot return, and what will be has never happened, because change, like substance, is logically ineluctable, through being part of the world of nature it is set in an unchangeable relation with other changes; in the psychic world - because the productions of psychological consciousness are based on the consequences of actual contents. In practical life, however, there is no absolute and permanent division between past and future facts; facts are past or future only in relation to actuality. Thus what was may return and what will be, can be; actuality divides phenomena into past and future differently. If something that we already know appears in actuality, that means that it was something future in relation to that actuality; sometime, however, it passed through consciousness, thus it belonged to the past. In other words, it moved from the past to the future in order again to sink into the past. They tell us that from the natural viewpoint these must be two separate natural phenomena; from the psychological viewpoint they mean two different experiences. Common sense will consider one of these phenomena to be reality and the other as a memory or foresight of the former. But if I remove all those explanations that arise on the ground of a cognitive contrast between the "thing in itself" and the "idea in itself," if I limit myself to that which is presented by a given phenomenon as an element of activity, I have to say that in cases of a return I am dealing with the same phenomenon, in so far as it has the same content, that is, in so far as we can consider its practical content to be the same. Foreseeing or remembering is a real element of activity, similar to a "perceived" phenomenon, which can be joined to the composition of the natural world. It is the same value, which only in other conditions appears in actuality, and another relation connects it with the rest of the values. But the question of its relation is another question; at this moment we are considering it as an element of practical reality.

We cannot thus say of any phenomenon that it is absolutely past or absolutely future. For as long as it may return, or still move from the past to the future, since it was foreseen, that means that it moved from the future into the past. What is absolutely past is only that which can no longer appear in actuality; absolutely future is that which cannot at all be foreseen. For practical life then, both absolute past and absolute future are nullities.

What then does that relativity of the past and future mean? It means that they are only directions of an emerging value: a future value is only 
that which is approaching actuality, a past value is one receding from it. A value can change its direction of becoming; it can successively approach and recede from actuality.

If now we want to define a value more specifically, let us say that it is an element of practical reality, practically considered in the entire process of its becoming, from the moment of its first emergence to the moment that it forever ceases to return to actuality. This means that a value, in contrast to substance, emerges and disappears; in contrast to experience, it endures through many "awarenesses." However, as a value is the more real the closer it is to actuality, we can say - in accord, after all, with common observation - that in the entire process of its becoming a value gradually moves from minimal reality to the highest reality and later again gradually approaches nothingness. At the beginning, it is rarely actual, later it appears in actuality increasingly often, until finally again its actualisation becomes rarer and then entirely ceases to occur. It is understood that these three periods - acquiring reality, the highest reality, and the loss of reality can have varying lengths. There are values that only once cross consciousness, to disappear forever: these include, for instance, the countless minor phenomena in the daily life of individuals. There are those that are long in preparation for their peak period and disappear shortly after achieving it, as, for instance, numerous of the so-called aims of individual strivings. There are others, which are also slow in preparation and disappear only with the death of the individuum - these are, for instance, the elevated ideals that give direction to a person's entire life. Some appear suddenly, at once achieve their peak period, and then long and slowly disappear: these are all the unexpected phenomena that shake the entire consciousness. Of course, all this diversity must be subject to a certain regularity, if indeed practical reality is not chaos but one world of values.

Let us emphasise thus that fundamental schema: the existence of values is a becoming, describing a fairly complicated wavy line, whose highest point - often in the middle, more rarely on either side, signifies moments of actuality. Of course, this is the simplest schema; numerous values have several peak periods.

If now we want finally to make a formulation of the contrast between a value and a thing (substance), we must remind ourselves that a value, considered in the individual moment of its actualisation, is a psychological experience. Every experience, given the continual changeability of values, obviously contains only a certain part - or certain side - of the entire content that a value possesses in the entire course of its duration. An experience contrasts with a thing through its incomplete, partial nature: a thing is that which appears in all experiences having a certain common content; only 
later, depending on various further factors, which we cannot here consider, sometimes more, sometimes fewer "properties" are excluded from the idea of the essence of the given thing as "subjective." The relation of a thing to experience is always such that in constructing the content of a thing we entirely overlook psychological time; we do not at all take into consideration in what successive order the experience of that thing occurred; even when we acknowledge the object to be objectively "changeable," the succession of experiences of that change has no significance for us, as experiences lose, in regard to things, their own individuality.

At the same time, for defining values, the order of the succession of moments of actuality is something quite significant, because those moments do not bave significance in themselves but only as links in the process of a value's becoming; they cannot be detached from what in the language of earlier psychology we would have called their "unconscious substrate." Thought detaches them in order to shape "things," but also from the viewpoint of practical experience, the "thing" is an abstraction. That abstraction also corresponds to abstract actuality, expressed in the concepts of an "ideal object," "reason," etc. absolute actuality, timeless, and not influencing the nature of phenomena.

If we were now to want to label the difference between a value and a thing, not from the viewpoint of practical experience but from the viewpoint of the rationalism of the thing, that difference is expressed in an unusually simple manner. A thing, a substance, constituting the unity of all the moments of the actualisation of a value, will be the logical boundary that a value approaches but is unable to reach in its successive and increasingly frequent actualisations. The second boundary set by values we will call nothingness, considering from the practical viewpoint that a value loses reality when it can no longer appear in actuality or is still entirely unforeseen. But that practical nullity is similarly not nonbeing, from the viewpoint of the logic of things, just as that highest reality that a value achieves in individual actuality during its period of most frequent actualisation is not a substantial being. From the factual standpoint, for nonexistence to be predicated of something, there must be a sufficient reason for the existence of something else; the world of values, in not achieving absolute being, cannot provide sufficient reason for absolute nonbeing. A value, for the logic of things, will thus not be something that has being, but something that is only becoming, that from nonbeing approaches substantial being, and contrarily, without ever reaching these two boundaries. Thus saying that the world of values "exists" is to express an apparently contradictory proposition. The contradiction, however, can be resolved. If a value does not achieve being 
it is because substantial being rests on the postulate of absolute actuality, in which the entire essence of a value could be real at once. At the same time, that essence of the value develops in time, and thus it is realised always only in a certain part; it can never be said from a substantial standpoint that a value has been completely realised and that it will not reveal a new side to its essence. But in exchange, it can also never be said that its becoming is finished. Thus the postulate of substantionalism can be answered by another postulate: that that becoming appears rationally as eternal, a value realising itself entirely in the duration of infinity, and thus its complete becoming means as much as being.

\section{III}

Considering a value from the logical-cognitive viewpoint, we were forced implicite to place the problem on the ground of individual consciousness. We were forced to do so by the traditional shaping of logical and epistemological questions, which again are in close relation with the all-powerful control of the logic of the thing. A thing is fundamentally independent of a specific thought process; actually thereby the very differentiation of individual and social conscious does not at all enter into play. Thinking in categories of material logic is de jure supra-conscious: thought of the absolute object. If it de facto occurs in consciousness, then the theoreticalcognitive problem that arises consists basically in studying by what manner a concrete consciousness raises itself to the level of the absolute object and can comprehend things as if they were independent of a specific thought process. It is not strange, since in this study individual consciousness was almost exclusively considered, that the theory of the relation of ideal and real thinking acquired the form of psychologism (with its various shades). What appears to us "from inside" is only individual thought; only in our own thought process do we make real an appraisal of phenomena and relations as cognitively positive or negative, that is, as correct or erroneous; and that appraisal is the basis for the construction of cognitive systems. Social thinking similarly only appears to us when it is our own thinking: the cognitive appraisal of the social group has cognitive significance for us only when we ourselves participate in it - when we think identically with the group. In these cases, obviously there is no need to differentiate social and individual consciousness. For cognitive theory, understood as a theory of correct or erroneous cognitive appraisals and the relations of those appraisals with their subjects, placing problems on the individual ground is 
thus entirely sufficient both on account of the ideal significance of material cognition as on account of its real process.

However, the question could appear different in the theory of values. We define a value in relation to the process of active consciousness, recognising actuality as an indicator of its emergence. Then, from a purely formal position, the question of the relation of social consciousness to individual consciousness must be defined. We take then the value "from the outside," not as an object of appraisal, but as a link of activity, and thus for us what is important is not only values, in the appraisal of which the individual consciousness agrees with the social consciousness, but entirely to the same degree those values which are subject to diverging appraisal from the individual and social standpoint. We must then consider whether the form that individual values possess can be extended to social values, and whether it is essentially the form of all elements of practical reality.

The original sin of the social sciences is not at all - as the extreme members of the sociological school claim - approaching the study of social phenomena from the viewpoint of the individual; the individual is not an abstraction in sociology any more than in biology, and although in the cultural individuum various social influences cross, yet the individuum gives itself reality by its own unique ordering of those influences in its own consciousness, and, as we shall see, does not increase nor lessen the difficulties arising in creating individual phenomena from social phenomena and vice versa. The entire cognitive problem of the relation of the individuum to the social arose from the false identification of the cultural human with the natural human, with transferring to the world of values certain ontological concepts that are valid only for the world of things.

The construction of the natural world required, as we mentioned above, supplementation in psychology, taking into account the sequence of phenomena in actuality as experiences. But further, it became necessary to harmonise these two worlds: the psychical and the natural, and activity unavoidably poses that question. For it, natural objects do not have an intangible nature: it enters the world of nature, introduces in it changes, which even from the natural standpoint cannot be denied; on the other hand, while occurring in actuality, they have a psychical nature. In the lack of a concept of a separate practical reality, a natural-psychological theory of the act cannot otherwise take into account that relatedness of the concrete consciousness with the world of nature but by introducing the world of nature into the composition of consciousness or understanding consciousness as part of nature. The first path is obviously, for psychology, impos- 
sible: a thing cannot be made into an experience; thus a consciousness, which things would be part of, must be a subconsciousness, an absolute object, or universal spirit. There remains thus only the other option: consciousness is introduced into the world of nature on the basis of its relation with the body understood as a natural organism. A human thus becomes a combination of organism and consciousness, a natural individuum; society is the synthesis of such natural individuals.

Of course, in this regard the problem of the relation of the individuum and society becomes insoluble. Experience, understood as the result of a certain relation of things and of the natural individuum, and being a self-existing phenomenon, is absolutely individual; the psychical life of the individuum - a self-enclosed whole; other individuals are only experiences. One thing, appearing to many people, becomes a multiplicity of separate experiences, which have nothing in common with each other; others' experiences can only be indirectly concluded and recreated in one's own consciousness, where, obviously, they become something entirely different, a new experience and not a recreation of the same one. It is only surprising that with such an understanding of the question attempts have been made to create social life from individual life; clearly either the doctrine was not sufficiently clearly understood or the obviousness of social experience pushed the doctrine to the background, where its inconsistencies could be borne.

These inconsistencies, though, are a bit too striking: thus there have been numerous attempts to eliminate them. It is a simple thing, however, that on the grounds on which the question is placed there was no solution other than defining society - that is, the sum of natural individuals - as a new natural whole, of which every individuum is a part. Thus society was likened to an organism - in various shades, from a complete likening of social life to an organism, as with Schäffle (today, with Novicow), through Spencer's formal but detailed analogy, to seemingly cautious premises which basically contain the seeds of a pure social "biologism."

The misunderstanding on which this theory rests can be indicated without difficulty. The individual organism is the basis of conscious phenomena: if there is to be an analogy between the individuum and society, then society as an organism can be only the social basis of conscious life. At the same time, social "biologism" makes conscious phenomena themselves into an element and organic link in the social system, that is, the social system is a metaphor expressing in a name drawn from biology certain relations occurring in time between social values. All the phenomena that this sociological school men- 
tions in order to show the analogy between society and the organism complexity of construction, functional differences, division of work, relation to other societies, social imagination, speech as a conveyor analogical to the nervous current, etc., etc. - all these are generalities which in organic life concern material phenomena constituting the equivalent of conscious life; in social life -conscious phenomena no longer have an equivalent. If, however, someone wanted to say that society is an organism precisely on account of the relations of those conscious phenomena that occur in it, that consciousness is such a form of social existence as anatomical build and physiological processes - the form of existence of the individual organism, in a word, that we are moving here to a new level of existence - in essence, we would have no objection, if it were not that the conclusion about the similarity of society and the organism is in that case at least premature. First, study of social life should be advanced sufficiently to claim that social phenomena significantly create relations analogical to the relations of biological phenomena in the organism. Yet when we commence the study of social elements we see at once that they appear entirely other than organic elements; they are values, not things, and thus we must first of all define their traits as the material of research; we cannot from the outset impose definitions for them, such claims that could sometime be a research finding. Of all metaphysics, this one of preceding concrete scientific findings on the basis of a priori premises or apparent analogies is the most dangerous.

However, even if we adopted that metaphysics, we would learn that even in abstracto it does not resolve the question of the individuum's relation to society. The individuum remains a psycho-physical entity; meanwhile, solely on account of its psychical side it participates in social life. The physical side remains a part of nature independent from society, and as an organism conditioning psychical phenomena brings to the social organism an irrational factor - individuality.

The strongest emphasis should then be put on the fact that the individuum must be absolutely detached from natural relations in order to understand its role as a part of social relations, in order for the question of the relation between individual and social phenomena not to be a "nest of sophisms" or a source of barren mysticism. The question is after all so simple that it is surprising that it needs to be clarified. The individuum is a part of nature only on account of its body; only as a result of the consciousness being attached to a body can we at all arrive at the concept of consciousness itself as something real, as a substance or function on the order of other substances, or a function within nature. A body appears to 
us consciously; it is the same content moving through actuality as other sensual or cultural content, in a word - it is a value among other values and not a condition or basis of others. That from a certain viewpoint, in creating a rational picture of the world, we arrive at a theory in which the body becomes the condition of consciousness after having been its part does not at all prove that we should remain at this same viewpoint forever, even though it turns out to be inappropriate for the solution of numerous questions. No less legitimate will be the position that keeps, for a body, the nature of a value - an important one, often the most important, influencing numerous facts in the world of values, but influencing them as an element of this world, as its part, and not as something outside of it. This viewpoint is essential for knowledge about practical reality, because here the body is only one - the most frequently encountered - of the elements of activity, or rather of a group of elements of activity. Practical, individual consciousness does not need a basis, because it is not something detached from practical reality and absolutely different, as psychical consciousness from natural reality; on the contrary, it is a certain process, a certain dynamic phenomenon, taking shape within practical reality and at the same time giving form to that reality.

Dividing in this manner the world of people from the world of nature, even understanding the latter as part of the first - since nature is to a significant degree, if not entirely, a work of knowledge about nature - we encounter two related trends that we must consider: the first we could call social psychologism and the second, ontologism.

Social psychologism, as it appears, for instance, in Wundt, is proof of how difficult it is to get rid of the belief that only natural phenomena can be considered as existing in itself, without regard for any - substantial or functional - soul, that would reflect it. Of course, as a value is described as an object of will, the existence of values will be dependent on the hypothetical subjective process that we call "will." The world of social values can thus be comprehended solely as a world of subjects of some "collective will," because value exists here only on account of the will, and will is an actual process, thus in the end the social world becomes the actuality of collective experiences, just as the individual world is the actuality of individual experiences. In other words, social values bear only the trait of collective psychical states, similarly to individual values - the principle of "as much reality as actuality" applies to them as well in the sense that outside of actuality there is no reality at all. 
It is easy to understand what consequences ensue therefrom both for the relation of individual phenomena to social phenomena and for research methods. A social value is a collective experience, thus basically when there is no collective experience, there is also no social phenomenon: values exist only in actuality. In this manner every individual experience, which is not shared at a given moment by other individuals, basically not only falls outside the borders of the social world but in general no relation between it and social phenomena can be established. Because the quantity of experiences that are actually common is extremely insignificant, it is necessary to turn to auxiliary means in order to count as social those phenomena of which various individuals at various moments become conscious. Social psychologism cannot use any auxiliary method other than the concept of psychical temperaments: the existence in the individual of a temperament to produce the same phenomenon which other individuals in other moments produce is sufficient to give social traits to that phenomenon. But in this manner we not only transfer the reality of social phenomena into the metaphysical area of will as an entity of the retaining temperament, but at the same time we leave an unresolved question: how can the social unity of the social fact be made to agree with the multiplicity of individual consciousnesses, since every individual experience, arising due to "temperament," will be a separate new fact?

Since, however, we only accept that values do not exist either in social or individual consciousnesses, but on the contrary, consciousness exists in the world of values and is a certain combination of them - the above problem can be resolved at once. The same value can enter into the composition of various combinations, either simultaneously or successively, just as the same natural object can be a link in numerous relations of identity and dependency. When the same content is given to many individuals, it does not at all mean that that content repeated itself that many times, was reflected in that many consciousnesses (beings), but simply means that it is a part of that many more or less changeable relations, because each individual connects with values differently. A value can thus be conceived as social entirely independently of whether it appears in many individuals at once or in each of them separately, or appears at all in many individuals. Between the individual and the social existence of values, there is no difference that could not be reduced to an empirical relation of that value with others: social reality and individual reality are the one sole reality, in which both the individuum and society are formed. The metaphysical problem of the relation of the individual consciousness to social consciousness will shatter into 
a quantity of simple empirical questions, each of which will concern the relation of combinations of one or another value in individual and social experience, or the relation of such or another individual value to such or another social value.

Just as we cannot accept social psychologism, we must also reject Durkheim's ontological school. According to that theory, social phenomena are objective realities, imposed on the individual in a fashion that is similarly independent of the individual, as are natural phenomena. Social ontologism derived from entirely justified strivings to obtain bases for positive sociological research; it is thus an absolute break with all social metaphysics; it cuts the knots that psychological cognitive theory tied; it ceases entirely to bring into play the problem of the relation of the individual psyche to the social psyche in the form of attempts to produce society from individuals. It thus has high methodological significance, shifting the emphasis of sociology from general abstract inquiries to the ground of concrete empirical studies of individual facts. But its methodology is closely connected with epistemology and the latter has not been critically grounded.

Viewing a social phenomenon as independent from the individuum of reality factually leads to repeating, on the basis of the world of values, the identical same division of reality and the individual psyche that produces it as we have on the basis of the world of things. Individual participation in a social phenomenon - the same as with a natural phenomenon - is simply the experience of that phenomenon, without influence on its nature. However, it is in social life that the influence of individual consciousness on phenomena cannot be denied or eliminated, as that influence is brought to the fore in acting, and social reality itself, in contrast to natural reality, is practical. Thus, for instance, when Durkheim excludes individual ideals from the range of moral reality, that abstraction is something entirely artificial because individual ideals gradually transform social norms. The premises of social ontologism lead to a voluntary limitation of the range of influences considered; actually, as well, it can be conducted only there where the Durkheim school predominantly applies it, namely in studying primitive societies, in which individual initiative is either essentially insignificant or cannot be, in our conditions, distinguished. In general, the influence of the individuum on shaping social phenomena is neither - as ontologism claims - nothing, nor is it unlimited, as social atomism claims; it is subject to infinite gradation; it is different in each specific instance, and the definition of social phenomena must be such as to allow for the 
consideration of those degrees and diversity. Solely our definition makes this possible.

Social values are for us independent of the individuum to the degree that their combination in collective life departs from the influence of their individual combination: those values that are independent of the individuum will obviously be first those values whose significance (that is, combination with others) is to a predominant degree the same for all individuals constituting the social group; those that are dependent will above all be those whose significance is not yet established and that are just being created, thanks to individual activity. In a word, we can say generally that the more durable the tradition the greater the social reality, and conversely: the individual character of a value will predominate the more production plays a larger role for it.

The general form of the value will, however, be identical with the entire extent of social and individual life. A value is everywhere a content whose existence is a becoming, a passage through actuality. It is thus a further question whether the moments of actualisation of a value will be more or less numerous and whether the value will be actualised for various individuals contemporaneously or successively, and whether the relations linking it with other values will be the same or differing in the experience of various individuals. At any rate, one thing should be emphasised: as the individual value appears completely only in the entirety of its process through all the successive moments of its actuality, so the social value appears only through its entire duration and in all the extension of its social influence through all the successive moments of its actuality in all individuals having the experience. Sociology cannot thus, in distinguishing values, detach them from individual differences in general, because this would mean the impoverishment of the content of the values by virtue of an a priori and voluntary criterion. It can take into consideration, from the content of a value, only that which is important for collective life, or that which for the studied relation between values has fundamental significance, but obviously what should be set aside and what retained cannot be resolved a priori. The criterion of importance is different in each individual case.

Since our definition of an individual value applies equally to a social value, the result is a good indicator for sociological research methods. Thus a social value must be considered in its emergence. It cannot be considered, as the psychological school often does, that any social phenomenon can appear entirely and be analysed at any one moment of its duration; it only reveals its fundamental content in the entire process of its becoming and 
disappearing. Thus it follows that all "pictures" of social life at a certain moment, which are so numerous especially in the history of literature, the history of art, etc., have absolutely no scientific significance.

That method (which has become especially widespread in comparative studies) should also be rejected that treats social values as things and takes institutions, beliefs, and law as something unchangeable, something that in the whole course of its duration preserves the same content. A characteristic thing is how many sociologists consider that the task of a comparative analysis is completed when, for instance, in a certain number of a social group the abstract existence of a similar belief, or social provision, legal norm, or institution is found - regardless of where they came from, in what connection, at what moment those phenomena emerged in various societies, how they developed, what occurs or occurred after them and so forth. This treatment of social phenomena as things has one of its main sources in the study of lower societies. In these societies, which we still have before our eyes today, the stagnation of conscious life is striking and even if changes occur, we lack historical evidence, similarly as with primary social groups which no longer exist. It proves, however, simply that lower societies are an inappropriate research subject for beginning sociology, with the exception of cases where the quantity of material already collected allows for the recreation of their evolution. However, we have before us historical humanity and a huge quantity of already partially prepared material. There, this principle - which moreover in this application becomes quite obvious - can be used in full: the social and individual world is one; it is practical reality, a world of dynamic values in which individuals and societies are formed.

Transl. Michelle Granas 